\title{
DISSEMINATED HYDATIDOSIS: A RARE CASE REPORT
}

\author{
B. S. Satish Prasad ${ }^{1}$
}

\section{HOW TO CITE THIS ARTICLE:}

B. S. Satish Prasad. "Disseminated Hydatidosis: A Rare Case Report". Journal of Evolution of Medical and Dental Sciences 2014; Vol. 3, Issue 74, December 29; Page: 15607-15609, DOI: 10.14260/jemds/2014/4106

ABSTRACT: Hydatid disease is a worldwide zoonosis produced by the larval stage of the Echinococcus tape worm.(1) We report the CT findings of a rare case of disseminated hydatid disease which was confirmed later by exploratory laparotomy.

INTRODUCTION: Hydatid disease primarily affects the liver and typically demonstrates characteristic imaging findings. Furthermore, secondary involvement due to hematogenous dissemination may be seen in almost any anatomic location (e.g. lungs, kidney, spleen, bone, brain).(1)

CASE REPORT: A 70 year female patient presented with a lump in the lower abdomen since 6 months. The lump had been gradually increasing over a period of time. Patient had persistent abdominal pain which was dull aching in nature localized to the lower abdomen. Physical examination revealed a large mass arising from the pelvis with gross hepatomegaly. Contrast enhanced CT revealed multiple cystic lesions in the abdomen and pelvis. The cysts were multi loculated with multiple internal septations suggestive of hydatid disease. The findings were confirmed by exploratory laparotomy.
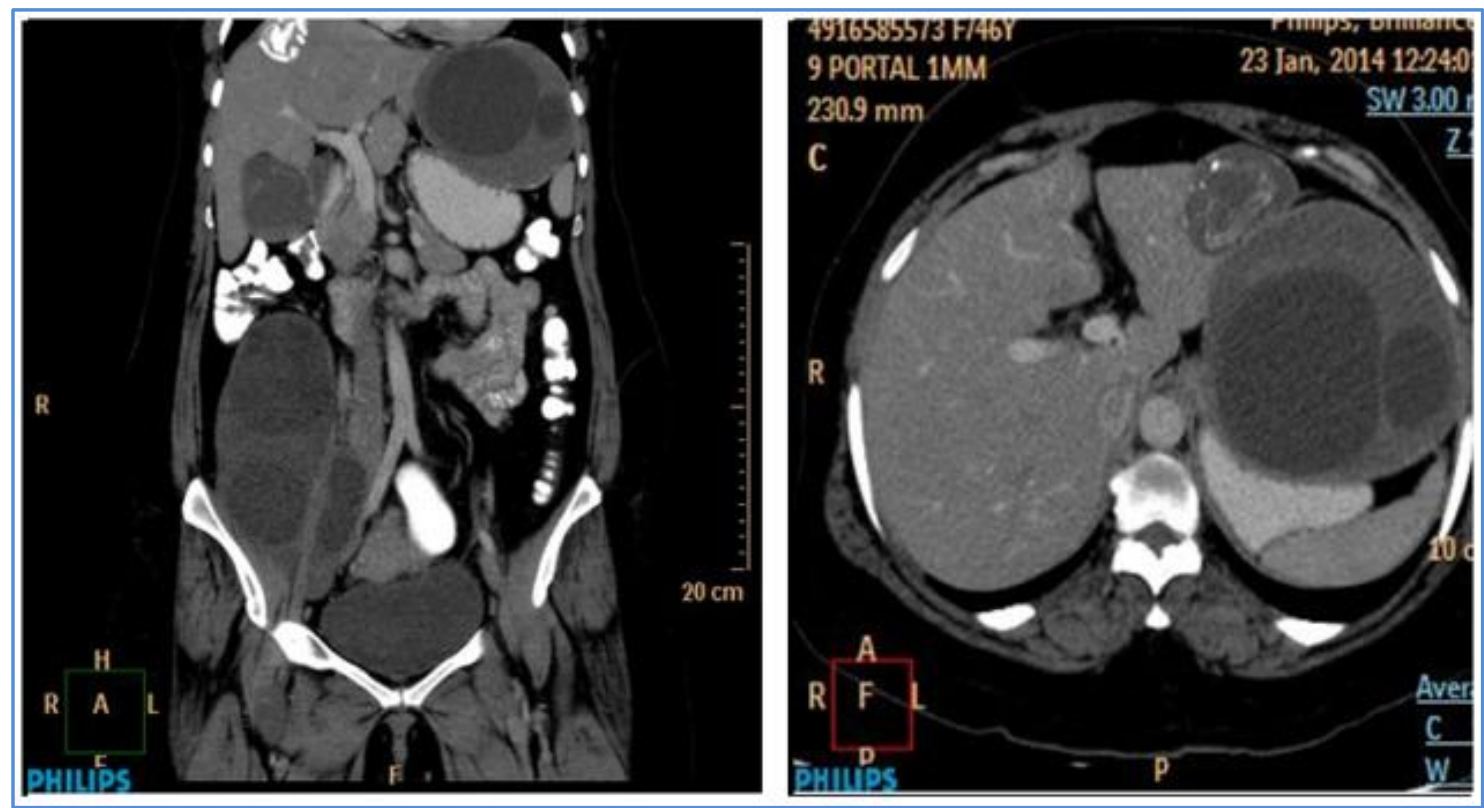

Fig. 1 \& 2: coronal and axial CECT images showing multiple cystic lesions in liver, spleen and pelvis suggestive of hydatid cysts 


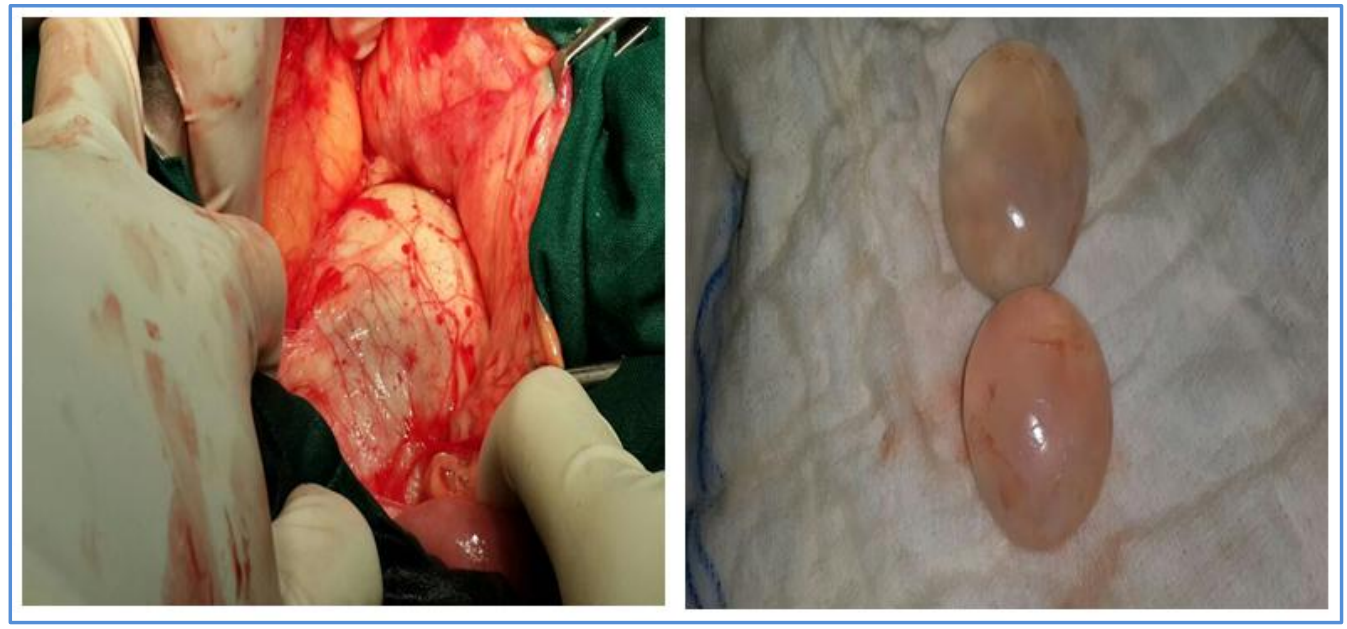

Fig. 3 \& 4: Intra-operative and post-operative images of hydatid cysts

DISCUSSION: The two main types of hydatid disease are caused by Echinococcus granulosus and Echinococcus multilocularis. Once the parasite passes through the intestinal wall to reach the portal venous system or lymphatic system, the liver acts as the first line of defense and is therefore the most frequently involved organ. In humans, hydatid disease involves the liver in approximately $75 \%$ of cases, the lung in $15 \%$, and other anatomic locations in $10 \%$.(1) It rarely involves the brain, heart, bone, or other organs. (2)

Many cysts never become symptomatic and regress spontaneously. If symptomatic, increased abdominal girth, hepatomegaly, a palpable mass, vomiting, or abdominal pain will be present.

The right lobe is the most frequently involved portion of the liver, usually antero-inferior segment. Imaging findings in hepatic hydatid disease depend on the stage of cyst growth.(3)

On CT, cyst fluid usually demonstrates water attenuation (3-30 HU). Calcification of the cyst wall or internal septa is easily detected at CT. A hydatid cyst typically demonstrates a highattenuation wall at unenhanced CT even without calcification. Detachment of the laminated membrane from the pericyst can be visualized as linear areas of increased attenuation within the cyst. Daughter vesicles manifest as round structures located peripherally within the mother cyst. CT also helps to differentiate hydatid cyst from amoebic or pyogenic liver abscess. ${ }^{(4)}$

On MRI, hepatic hydatid cysts may have a low-signal-intensity rim on T2W images. Daughter cysts are seen as cystic structures attached to the germinal layer that are hypointense relative to the intracystic fluid on T1W images and hyperintense on T2W images.(5)

of the serologic tests, the indirect hemagglutination test and the Casoni skin test have approximately an $85 \%$ sensitivity.

DIFFERENTIAL DIAGNOSIS: Amoebic liver abscess, Pyogenic liver abscess, Hepatic adenoma, Hepatic carcinoma, hepatic cysts, metastatic lesions.

CONCLUSION: Hydatid disease primarily affects the liver and typically demonstrates well-known, characteristic imaging findings. However, there are many potential local complications, and 
secondary involvement due to hematogenous dissemination may be seen in almost any anatomic location. Familiarity with atypical manifestations of hydatid disease may be helpful in making a prompt and accurate diagnosis.

\section{REFERENCES:}

1. Iván Pedrosa, MD, Antonio Saíz, MD. Hydatid Disease: Radiologic and Pathologic Features and Complications. Radiographics 2000; 20: 795-817.

2. Engin G et al. Hydatid disease with unusual localization. European Radiology 2000; 10: 19041912.

3. Thambidurai L, Santhosham R, Dev B. Hydatid cyst: Anywhere, everywhere. Radiology Case Reports 2011; 6: 486.

4. Hassan AU, Obaid, Shafi S, Hassan MU, Rather A. Hydatid disease of liver and disseminated hydatidosis: anatomical, microbiological and radiological perspective. Int J Res Med Sci 2013; 1: 188-90.

5. Engin G et al. Hydatid disease with unusual localization. European Radiology, 2000, 10: 19041912.

\section{AUTHORS:}

1. B. S. Satish Prasad

\section{PARTICULARS OF CONTRIBUTORS:}

1. Professor \& HOD, Department of Radiodiagnosis, Adichunchanagiri Institute of Medical Sciences.

\section{NAME ADDRESS EMAIL ID OF THE CORRESPONDING AUTHOR:}

Dr. B. S. Satish Prasad, \# 214/Y, $3^{\text {rd }}$ Block, 53 ${ }^{\text {rd }}$ Cross, $13^{\text {th }}$ Main, Rajaji Nagar, Bangalore-560010.

E-mail: satishprasad.bs@gmail.com

Date of Submission: 11/12/2014.

Date of Peer Review: 12/12/2014.

Date of Acceptance: 19/12/2014.

Date of Publishing: 29/12/2014. 